\title{
Correction to: Mathematical modeling and intelligent optimization of submerged arc welding process parameters using hybrid PSO-GA evolutionary algorithms
}

\author{
Ankush Choudhary ${ }^{1} \cdot$ Manoj Kumar $^{1} \cdot$ Munish Kumar Gupta $^{2} \cdot$ Deepak Rajendra Unune $^{1}$. \\ Mozammel Mia $^{3}$
}

Received: 23 August 2019/Accepted: 28 August 2019/Published online: 5 September 2019

(C) Springer-Verlag London Ltd., part of Springer Nature 2019

\section{Correction to: Neural Computing and Applications https://doi.org/10.1007/s00521-019-04404-5}

In the original publication, the fourth author name was incorrectly published. The correct name is Deepak Rajendra Unune.

Publisher's Note Springer Nature remains neutral with regard to jurisdictional claims in published maps and institutional affiliations.

The original article can be found online at https://

doi.org/10.1007/s00521-019-04404-5.

\section{Ankush Choudhary}

ankush.choudhary@lnmiit.ac.in; ankushmasand@gmail.com

1 Mechanical-Mechatronics Engineering, The LNM Institute of Information Technology, Jaipur, Rajasthan, India

2 Key Laboratory of High Efficiency and Clean Mechanical Manufacture, Shandong University, Jingshi Road, Jinan, China

3 Mechanical and Production Engineering, Ahsanullah University of Science and Technology, Dhaka, Bangladesh 